\title{
Nuevos registros y redescubrimiento de dos especies de Blakea (Melastomataceae) en Chocó, Colombia
}

\section{Report news and rediscovey of the two Blakea's species (Melastomataceae) of the Chocó, Colombia}

\section{Zulmary Valoyes Cardozo, Biol ${ }^{1}$, María Eugenia Morales-Puentes, MSc, PhD (c) ${ }^{2}$}

\section{RESUMEN}

Se amplía la lista de especies de Melastomataceae del departamento del Chocó, con ocho taxones del género Blakea (Melastomataceae) (B. andreana, B. cuatrecasii, B. megaphylla, B. pilosa, B. stipulacea y B. vallensis), así como el redescubrimiento de $B$. paleacea y $B$. platypoda; se dan a conocer detalles de las características deflores, frutos y semillas de dichos taxones. Se presentan las descripciones ampliadas de las especies, así como datos sobre distribución, clave taxonómica, fotografias, información del hábitat y fenología.

Palabras clave: Redescubrimiento de dos especies de Blakea; Blakeeae; Nuevos registros para el Chocó; Melastomataceae.
1. Grupo Biosistemática, Universidad Tecnológica del Chocó «Diego Luis Córdoba», apartado aéreo 292, Quibdó, Colombia.

e-mail: zulmaryvaloyes@gmail.com

2. SisBio, Escuela de Ciencias Biológicas, Universidad Pedagógica y Tecnológica de Colombia, Tunja, Boyacá, Colombia.

e-mail: mmoralespuentes@yahoo.com Recibido: 14 de agosto de 2011

Aceptado: 20 de septiembre de 2011

\section{ABSTRACT}

It is broaden Melastomataceae species list in Chocó state, with eigth Blakea (Melastomataceae) genera taxas (B. andreana, B. cuatrecasii, B. megaphylla, B. pilosa, B. stipulacea and B. vallensis), as well as B. paleacea y B. platypoda rediscovering; It is released details flowers, fruits and seeds features about it. It is exhibited a species broaden descriptions, and dates refering distributions, taxonomic key, photos, habitat information and fenology.

Keywords: Rediscovery Blakea; Blakeeae; Chocó; Melastomataceae; Morphology.

\section{INTRODUCCIÓN}

El género Blakea P. Brown (Melastomataceae), se encuentra circunscrito a la tribu Blakeeae, que tiene tres géneros y aproximadamente 210 especies (Morales-P. et al. 2007, Penneys 2007).

Blakea está constituido por unas 100 especies, cuyos caracteres diagnósticos están centrados en el androceo, (anteras oblongas a robustas, cortas, obtusas, lateralmente comprimidas, conectivo prominente con base prolongada en una espuela cónica y dos diminutos poros apicales); hábito arbóreo, arbustivo o enredaderas leñosas frecuentemente epífitas (Almeda 1990, 2000a). Este género ha sufrido muchos cambios en su historia nomenclatural; recientes estudios ubican a Topobea, que anteriormente constituía un género de la tribu Blakeeae, en la sinonimia de Blakea aumentando su número de especies a 216 (Penneys 2007).
El género Blakea tiene distribución neotropical, desde Chiapas en México hasta el sur de Bolivia y Brasil, con dos especies en Jamaica y una en las Antillas Menores (Penneys 2007). Presenta su mayor diversificación en Colombia, con unas 50 especies y una fuerte concentración de endemismos a lo largo del Andén Pacífico en los departamentos de Nariño, Valle y Chocó, donde se concentra el mayor número de especies (Uribe 1971; Wurdack 1973, 1980; Almeda 1974; Calderón y Mendoza 2000), donde ocupan una variedad de hábitats, que van desde el nivel del mar hasta los 2800 m (Mendoza y Ramírez 2006); con una variedad de adaptaciones florales que reflejan la amplia gama de polinizadores, que incluye redores, abejas y murciélagos (Almeda 1990, Lemur 1981).

Recientes estudios de Blakea (Valoyes 2008, Penneys 2007), han permitido ampliar el conocimiento del género para el neotrópico, así como para la región Pacífica colombiana, con el registro de ocho especies para la flora chocoana 


\section{Bioetnia Volumen 8 No 2 (julio-diciembre), 2011}

(Blakea andreana, B. cuatrecasii, B. megaphylla, B. pilosa, B. stipulacea, B. vallensis, B. paleacea y B. platypoda). $B$. paleacea Gl. y B. platypoda Gl., descritas y publicadas por Gleason (1945), se basan en las colecciones realizadas por José Catrecasas en el año de 1944; recientes colecciones efectuadas en San José del Palmar, Nóvita y otras localidades del departamento del Chocó, permiten ampliar su distribución y a su vez detallar sus flores; igualmente, se describen los frutos y las semillas, estructuras que no se encuentran en la descripción original, porque el material tipo carece de dichas estructuras.

En este trabajo se presentan descripciones ampliadas de los taxones mencionados anteriormente, de los cuales, solo existían registros para el departamento del Valle del Cauca y en algunos casos para Nariño; asimismo se proporcionan detalles de los caracteres florales, de los frutales y de las semillas, así como datos de distribución, fenología y hábitat.

\section{MATERIALES Y MÉTODOS}

Se utilizaron las técnicas clásicas en taxonomía vegetal. Se realizaron salidas de campo a diferentes municipios del departamento del Chocó, igualmente se consultaron colecciones depositadas en los herbarios colombianos CHOCÓ, COL, CUVC, HUA, JAUM, MEDEL y las bases de datos MO, NY, KEW. Para la terminología de las estructuras morfológicas se siguió a Font Quer (1982), Hickey (1973) y Moreno (1984). La determinación de las especies se realizó con el uso de las claves de Gleason (1945), Wurdack (1973, 1980), Almeda (1990, 2000, 2001) y especialistas.

\section{RESULTADOS Y DISCUSIÓN}

Los muestreos en diferentes localidades del departamento del Chocó, la revisión de los principales herbarios de Colombia y las bases de datos de algunos herbarios virtuales, permiten ampliar la lista de especies de este taxón para la región, aumentando el número de especies de cuatro a diez; los recientes registros amplían el rango de distribución de estas especies que únicamente se reportaban para la región del Valle del Cauca. A continuación se presenta una clave, datos de hábitat, distribución, fenología de las especies mencionadas, además de las descripciones ampliadas e imágenes de las dos especies que se constituyen como redescubrimientos.

\section{CLAVE DE LOS NUEVOS REGISTROS DE LAS ESPECIES DE BLAKEA EN EL DEPARTAMENTO DEL CHOCÓ}

1. Plantas sin estípulas

2. Pecíolos acanalados, alados, 4-6 cm de longitud; flores con brácteas libres, cóncavas; pétalos unicóloros, blancos; estigma globoso ..................... B. platypoda $2^{1}$. Pecíolos teretes, de $2-3 \mathrm{~cm}$ de longitud; flores con brácteas connadas, con diferentes grados de fusión, nun ca libres; pétalos bicoloros; estilo cilíndrico, levemente uncinado; estigma truncado

3. Ausencia de lenticelas en las brácteas

B. vallensis

$3^{1}$. Lenticelas presentes en las brácteas

4. Flores con pétalos reflexos; cáliz entero; semllas piramidales. B. cuatrecasii $4^{1}$. Flores con pétalos erectos; cáliz lobulado; semillas en forma de hoz. B. andreana

$1^{1}$. Plantas con estipulas

5. Hojas con 11-13 nervios; cáliz lobulado con venas anastomosadas; corola con pétalos obovados.

6. Estípulas enteras, beige; pecíolos teretes, glabros, hojas ovada-elípticas; pedicelos con 19 mm de longitud; brácteas ovado-oblongas, con ápice redondeado, cóncavas, lenticeladas y multinervadas; inflorescencias con más de 20 flores por axila; flores con estilo uncinado cubierto por trico mas eglandulares y estigma truncado.

B. megaphylla

$6^{1}$. Estípulas laceradas, pardo oscuras; pecíolos acanala dos, con indumento dendrítico. $22 \mathrm{~cm}$ de longitud; pedicelos de 1,5-2 cm de longitud; brácteas ovado-lanceoladas, con ápice acuminado, sin lenticelas; inflorescencias con 2-10 flores por axila; flores con estilo cilíndrico cubierto por tricomas glandulares y estigma subgloboso....

B. paleacea

$5^{1}$ Hojas con 5-7 nervios; cáliz lobulado sin venas anastomosadas; corola con pétalos oblongo-lanceolados 7. Peciolos de 4,5-5 cm de longitud; hojas con cinco nervios, 27,5-35 x 12-16 cm, margen entera; Pétalos oblongo-lanceolados, rojos..................... pilosa $7^{1}$ Peciolos de 2,5-4 cm de longitud; hojas con 7nervios, 10-17 x 4-8,5 cm, margen dentada;

Pétalos oblongos, rosados. B. stipulacea 


\section{DESCRIPCIÓN DE LAS ESPECIES}

1. Blakea andreana Cogniux, Bull. Acad. Roy. Sci. Belgique ser. 3, 14: 969 (1887). Tipo: COLOMBIA. Valle del Cauca: alto del Potrerito, 1800 m, 1876, E. André 2691 (NY Imagen digital!).

Hábitat, distribución y fenología. En Colombia se encuentra distribuida en Antioquia, Boyacá, Norte de Santander, Valle del Cauca y Putumayo; en el Chocó se conoce por tres colecciones realizadas en San José del Palmar, crece principalmente en borde de carretera, en bosques lluviosos, nublados, entre los 1500-2500 m. Floración en los meses de julio y noviembre, con frutos en noviembre.

Observaciones. Entre las especies de Blakea presentes en el departamento del Chocó, $B$. andreana es la única que presenta flores grandes, de 4,2-5,3 × 3-3,1 cm, pétalos no reflexos, cáliz lobulado con lóbulos profundos, afines a $B$. cuatrecasii y $B$. vallensis, que exhiben flores de $12 \mathrm{~mm}$ y 28 $\mathrm{mm}$ de longitud $\mathrm{x} 17,5 \mathrm{~mm}$ de diámetro y cáliz fusionado. $B$. andreana posee estilo cubierto por pequeños tricomas blancos; frutos con ocho lóculos; semillas triangulares en forma de hoz, de 0,4 $\mathrm{mm}$ de longitud x 0,2 $\mathrm{mm}$ de diámetro, características que la diferencian de sus afines (ver observaciones de B. cuatrecasii y B. vallensis). A esta especie, a pesar de presentar flores muy vistosas y ecológicamente desempeñar un papel importante en los ecosistemas, no se le conoce ningún uso, razón por la cual es ignorada en los trabajos florísticos.

Material examinado. COLOMBIA. Chocó: San José del Palmar: hacia El Galápago, 11 nov 1985, G. Lozano et al. 4887 (COL); Galápago, 04 50'09.5"N, 76² 12'01.5"W, 1856 m, 28 jul 2007, Valoyes Z. et al. 277 (CHOCO).

2. Blakea cuatrecasii Gleason, Bull. Torrey Bot. Club. 72: 387. 1945. Tipo: COLOMBIA. Valle del Cauca: vertiente occidental de la cordillera Occidental, hoya del río Dagua, 900-1180 m, 12-28 ago 1943, J. Cuatrecasas 15180 (Holótipo, NY foto!, Isótipos, COL!, CAS, F, US).

Hábitat, distribución y fenología. En la región mesoamericana se registra para el oeste y centro de Panamá (Almeda 2000); en Colombia se registra en Antioquia, Cauca, Valle del Cuaca y Chocó; en éste último, se conoce por tres colecciones realizadas en los municipios de San José del Palmar, Unión Panamericana (Salero), $\mathrm{km} 7$ vía Yuto; crece principalmente en bordes de caminos y carreteras, en bosques húmedos, nublados, entre los 100-2300 m. De esta especie se han colectado individuos florecidos en febrero, julio, septiembre, diciembre y fructificados en julio.

Observaciones. Blakea cuatrecasii se reconoce por las brácteas externas fusionadas en la base; flores adaxialmente blancas y abaxialmente blancas con tintes fucsia; estambres dispuestos en un semicírculo (formando ángulos de $180^{\circ}$ ), anteras comprimidas lateralmente, con conectivo prolonga- do en un espolón cónico apical; $B$. cuatrecasii es afín a $B$. andreana, pero se diferencia de esta última, porque sus hojas tienen escasa pubescencia y las flores son más pequeñas ( 28 $\mathrm{mm}$ de longitud), cáliz entero; pétalos completamente reflexos; pistilo glabro y frutos con 6-lóculos; semillas obpiramidales, levemente estrechas o angulosas.

Se observó gran variación en cuanto al hábito de crecimiento, tamaño y forma de las hojas, presencia o ausencia de indumentos y color de los pétalos de esta especie; en zonas bajas (45-50 msnm) se observa hemiepifita; hojas obovadas, semicoriáceas, de $6 \times 3 \mathrm{~cm}$, nerviación poco pronunciada; flores con colores vivos (blanco y fucsia); en zonas altas (1000 msnm) se han observado arbusto o pequeños árboles; hojas de $15 \times 7,5 \mathrm{~cm}$, nerviación pronunciada por el envés, flores con una coloración pálida (blanco y rosado). Blakea cuatrecassi expresa gran variabilidad en el tamaño, tipos de habito y forma de las hojas, coloración de los pétalos y diferentes grados de fusión en las brácteas. Almeda (2000), manifiesta que este taxón exhibe gran plasticidad en el tamaño de las hojas y grado de fusión de las brácteas, características que permiten dificultad en su identidad taxonómica.

Material examinado. COLOMBIA. Chocó: Quibdó km 7, vía Quibdó-Yuto, enseguida de estadero Kalima, 05³7'28.9" N, 76³8'17.9" W, 129 m, 16 sep 2007, Valoyes Z. \& L. Palacios 357 (CHOCO); Unión Panamericana, Salero, 13 abr 2007, Valoyes Z. \& J. J. Cuestas 241 (CHOCO); Quibdó, km 7, finca Panelita, 02 feb 2008, Valoyes $Z$. \& L. Palacios 394 (CHOCO); San José del Palmar: Las Partidas, 1078 m, 28 jul 2007, Valoyes Z. et al. 329 (CHO$\mathrm{CO})$.

3. Blakea megaphylla Wurdack, Phytologia VI.2 (1957). Tipo: COLOMBIA. Valle del Cauca: río Cajambre, costa Pacífica, 5-80 m, 5-15 may 1944, J. Cuatrecasas 17504 (Holótipo NY foto!, Isotipo F).

Hábitat, distribución y fenología. Endémica del Andén Pacífico, se ha registrado en Chocó y Valle del Cauca. En Chocó se conoce por dos colecciones realizadas en San José del Palmar y Novita, crece principalmente en borde de carretera en sitios pendientes en el bosque intervenido, a una altura de 100-1100 m. De esta especie se han colectado individuos florecidos en los meses de febrero, julio y fructificados en el mes de julio.

Observaciones. Blakea megaphylla, es afín a B. jativae (endémica de Ecuador); ambas especies presentan múltiples estipulas nodales; sin embargo, en B. jativae estas estípulas son laceradas, papiráceas, de color pardo, mientras $B$. megaphylla las estípulas son enteras, membranáceas, blanco-beiges, que emiten un olor fuerte y se encuentran cubriendo los primordios foliares y los botones florales.

Blakea jativae posee hojas obovadas con nueve nervios; inflorescencias de 2-4 flores por nudo; mientras B. megaphylla 


\section{Bioetnia Volumen 8 No 2 (julio-diciembre), 2011}

presenta hojas ovadas-elípticas con 13 nervios; inflorescencias con hasta 60 flores por axila; hipanto levemente costillado, este taxón se encuentra dentro del grupo de especies afines a B. subconnata.

Material examinado. COLOMBIA. Chocó: San José del Palmar, vía que conduce a La Italia a 1078 m, 26 jul 2007, Valoyes Z. et al. 293 (CHOCÓ); Las Partidas, 0453'38.2" N, 76 14'33.0" W, 1078 m, 28 jul 2007, Valoyes Z. et al. 324 (CHOCÓ); San Juan, Nóvita, vereda Llanadas, ladera norte cerro del Torrá, entre 600-900 m, 22 feb 1977, E. Forero et al. 3078 (COL).

4. Blakea paleacea Gleason, Bull. Torrey Bot. Club. 72: 389.1945. Tipo: COLOMBIA. Valle del Cauca, costa pacífica, río Cajambre: quebrada de Ordoñez, 5 m, 1 may 1944, J. Cuatrecasas 17271 (Holótipo NY foto!, COL!) Figura 1.

Descripción enmendada. Planta arbustiva a veces hemiepífita, 2-4 m de altura. Tallo con entrenudos, teretes cubierto por indumento de color pardo claro, nudos cubiertos por estípulas laceradas pardo oscuras; pecíolos acanalados, $22 \mathrm{~cm}$ de longitud x 1,5 mm de grosor, con la superficie cubiertas por indumento pardo claro; hojas ovadas, de 45,5 x $31 \mathrm{~cm}, 11$ nervios cubiertos por densas escamas, base redondeada, ápice acuminado, margen entera. Inflorescencia axilar, con 2-10 -(60) flores por axila; pedicelos de 3-4 cm de longitud x $2 \mathrm{~mm}$ de grosor; brácteas elípticas, cóncavas, 12 14 × $8 \mathrm{~mm}$, ápice acuminada-agudo, base truncada, membranosas, multinervadas; hipanto de $4.5 \mathrm{~mm}$ de longitud x 4,6 de diámetro glabro, verde claro; cáliz lobulado, mucronato, $2 \mathrm{~mm}$ de longitud, tubo del cáliz de $1 \mathrm{~mm}$, lóbulos de 2 × 3,5 mm, verdoso con venas anastosomadas; pétalos obovados, 11,5 x $9 \mathrm{~mm}$, margen ciliado de color rosado; estambres de $7 \mathrm{~mm}$ de longitud; filamento de $3 \mathrm{~mm}$ de longitud; anteras de 4 x 1,7-2 mm; poros ovoides, $0,2-0,3 \times$ $0,2 \mathrm{~mm}$, distancia entre los poros de $0,3 \mathrm{~mm}$; ovario $6-$ carpelar, ínfero, ápice del ovario de $2 \mathrm{~mm}$ de longitud; estilo cilíndrico de $9 \mathrm{~mm}$ de longitud, cubierto por tricomas glandulares; estigma subgloboso. Frutos globosos, inmaduros rosados-blancuzcos, maduros fucsia; semillas obovadas, alargadas y estrechas, arqueadas en la parte media, base aguda, ápice redondeado, 1,1-1,2 mm de long, superficie lisa con leves estriaciones longitudinales, glabra; rafe expandido más ancho en el ápice que en la base.

Hábitat y distribución. Especie endémica del Andén Pacífico, se conocía por la colección tipo, del Valle del Cuaca hace 63 años (Gleason 1945); colecciones recientes en Chocó amplían la distribución, actualmente se ha colectado en los municipios de San José del Palmar y Nóvita, crece principalmente en borde de carretera, bosques nublados a una altura de 60-1860 m. De esta especie se han colectado individuos florecidos en el mes de febrero, octubre y fructificados en los meses de abril y julio.

Observaciones. Blakea paleacea hace parte del grupo de especies afines a B. subconnata; sin embargo, se diferencia por presentar hojas de 45,5 x $31 \mathrm{~cm}$, pecíolos hasta $22 \mathrm{~cm}$ de long; estípulas nodales, laceradas, pardo oscuras; hipanto terete; pétalos con margen ciliado; estilo cubierto por tricomas glandulares; es afín a $B$. florifera, pero se diferencia porque esta última presenta indumento setoso abundante que cubre todas las estructuras vegetativas.

Esta especie presenta un área de distribución entre los 600-1800 msnm, lo que puede estar relacionado con el tipo de dispersores que presenta un rango de movilidad en esa franja altitudinal, y que puede estar induciendo a que morfológicamente no se encuentren variaciones en las características físicas de esta especie, es decir, presenta menor grado de plasticidad que sus afines.

Material examinado. COLOMBIA. Chocó: San José del Palmar, vereda San Antonio, 1860 m, 03 abr 2007, Valoyes Z. et al. 210 (CHOCÓ); vereda San Antonio, $04^{\circ} 50^{\prime} 08.5^{\prime \prime} \mathrm{N}, 76^{\circ} 12^{\prime} 27.0^{\prime \prime} \mathrm{W}, 1860 \mathrm{~m}, 25$ jul 2007, Valoyes Z. et al. 280 (CHOCÓ); San José del Palmar, hoya del río Torito, 15 mar 1980, Forero E. et al. 7368', $7368^{2}$ (COL); San José del Palmar, 1550 m, 14 nov 1978, Lozano G. \& J. Díaz 3045ㄴ $3045^{2}$ (COL); San Juan, Nóvita, vereda Llanadas, ladera norte cerro del Torrá, entre 600-900 m, 22 de feb 1977, Forero E. et al. 3106 (COL).

5. Blakea platypoda Gleason, Bull. Torrey Bot. Club, 72: 390.1945. Tipo: COLOMBIA. Valle del Cauca, costa del Pacífico, río Calambre, 5-80 m, 20-21 abr 1944, Cuatrecasas J. 17027 (Holótipo NY foto!) (Figura 2).

Descripción enmendada. Planta arbórea, terrestre, frecuentemente hemiepífito, 8-12 $\mathrm{m}$ de altura. Ramas subrectangulares, con entrenudos glabros; pecíolos acanalados, alados rojizo-purpura, 4-6 x 1,5-2 cm. Hojas obovadaselípticas, subcoriáceas, 17-24 x 11-16 cm, base obtusa, ápice acuminado, glabras o cubiertas por indumento, pardo claras. Inflorescencia axilar; flores de 2-4 por axila; pedúnculos de $2,5 \times 0,3 \mathrm{~cm}$, cubierto por lenticelas; brácteas subredondeadas, cóncavas, subcoriáceas, libres, cubiertas por lenticelas blancas, ápice acuminado; brácteas externas de $27 \times 16$ $\mathrm{mm}$; brácteas internas de $25 \times 30 \mathrm{~mm}$; hipanto de $7-9,5 \mathrm{~mm}$ de longitud x 7,8-8 mm de diámetro, verde-amarillento, con costillas poco pronunciadas; cáliz de 3-4 mm de longitud, verde pálido, tubo del cáliz de $2 \mathrm{~mm}$ de long; sépalos lobulados, 3,5 x 7,2 mm, con venas anastosomadas, con un diente brevemente ápiculado; pétalos obovados, reflejos, 18-20 x 15-16 mm, margen ciliado, blancos; estambres 12, 14-17 mm de longitud; filamento blanco de 11 x $2 \mathrm{~mm}$; anteras oblongas, connadas, 8,9-9 × $3 \mathrm{~mm}$, adaxialmente blancas, abaxialmente purpura claras, tecas de 7,5 x $2 \mathrm{~mm}$, dos poros ovoides, apicales, separados, 0,5 x 0,4 mm, distancia entre poros de $0,3 \mathrm{~mm}$; conectivo poco prolongado, a manera de espuela, blanco; ovario con ápice de $1 \mathrm{~mm}$ de longitud, costillado, 6-carpelos; estilo de $28 \mathrm{~mm}$ de longitud 

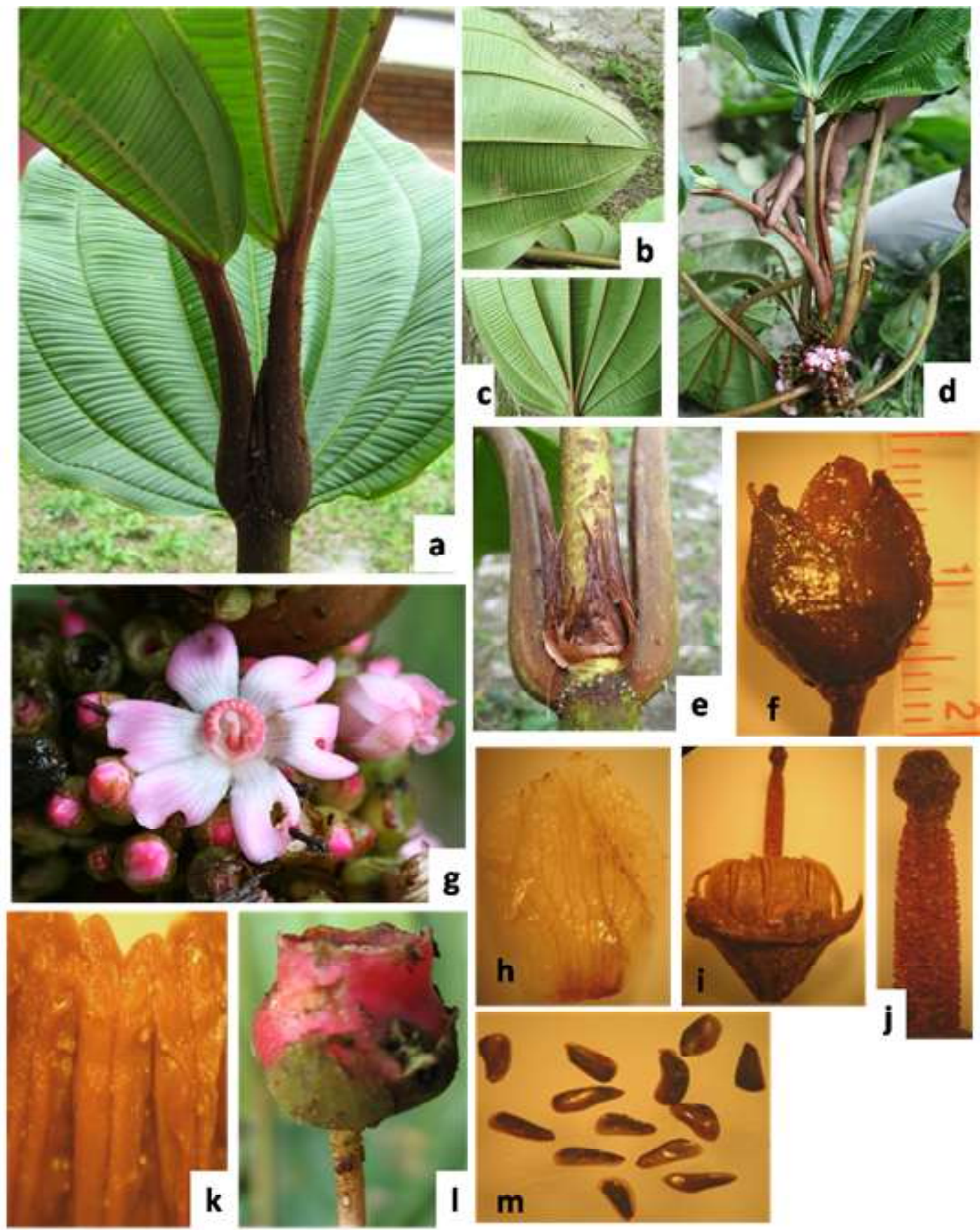

Figura 1. Blakea paleacea Gleason. a) hábito, b) ápice, c) base, d) inflorescencia, e) estipulas, f) botón floral, g) flor, h) pétalo, i) detalle del hipanto y caliz estilo, j) estilo y estigma, $\mathbf{k}$ ) detalle de las anteras y poros, I) fruto juvenil, $m$ ) semillas (Valoyes et al. $210 \mathrm{CHOCO}, \mathrm{COL}$ )

x $1 \mathrm{~mm}$ de diámetro, blanco, cubierto por pequeños tricomas simples; estigma globoso. Fruto en baya inmadura, amarilla pálida y cuando madura es fucsia.

Hábitat y distribución. En Colombia esta especie se ha registrado para el Andén Pacífico en el Valle del Cauca,
Nariño y Chocó, en éste último se conoce por colecciones realizadas en los municipios de Quibdó en las localidades de Tutunendo (km 7, vía Yuto), Unión Panamericana (Salero) y San José del Palmar; crece principalmente en borde de carretera, bordes de camino en bosques lluviosos, nublados, 

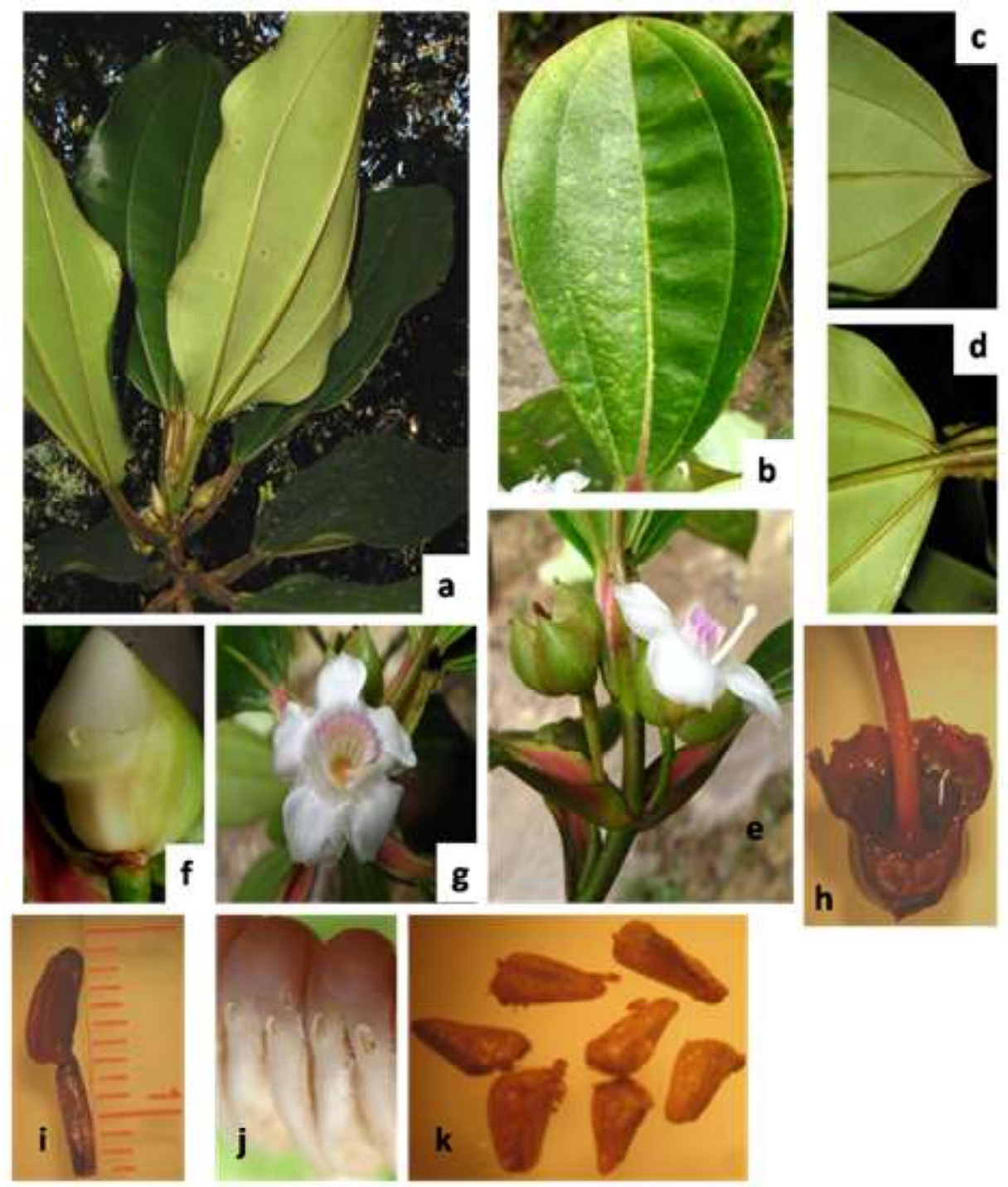

Figura 2. Blakea platypoda Gleason, a) hábito, b) haz, c) ápice, d) base, e) inflorescencia, f) botón floral, $g$ ) flor, $h$ ) detalle en orte longitudinal de la flor, i) antera, j) detalle de las antenas y los poros, k) semillas (Valoyes et al. 376 CHOCO, COL).

a una altura entre los 0-1700 m. De esta especie, se han colectado individuos florecidos y fructificados en los meses de enero, abril, julio, agosto y octubre.

Observaciones. Blakea platypoda es afin a B. subconnata, se diferencia de esta por poseer entrenudos cuadrangulares sin alas; pecíolos acanalados, alados, rojizos a morados; pétalos completamente reflexos, blancos. Mientras que B. subconnata presenta entrenudos con alas conspicuas; pecíolos acanalados; pétalos reflexos hasta un $30 \%$, rosado claros a fucsia.

Blakea platypoda presenta variabilidad en el hábito, tamaño y forma de las hojas, lo que posiblemente está relacionado con variables ambientales como clima, altura, etc., esto hace que en zonas bajas esta especie tenga un hábito de crecimiento hemiepífito y en zonas altas sean arbolitos, y además que modifique estructuras externas como el tamaño y color de los pecíolos y forma de sus hojas; en zonas bajas son de 2,7-4,2 x $17 \mathrm{~mm}$, con un canal de fondo rojizo y la forma y tamaño de sus hojas obovada, $13,5-19 \times 7,5-10 \mathrm{~cm}$. Mientras que en zonas altas estos pecíolos son de 4-6 x 1,3 $\mathrm{cm}$, con el canal de fondo pardo y las hojas de forma ovadoelípticas, 17-24 x 11-16 cm, membranáceas, cubiertas por indumento pardo claro; pétalos con margen ciliado. Del mismo modo se presenta la adquisición o disminución de indumentos en órganos como sus flores; flores con pétalos glabros en zonas bajas, y pétalos con pequeños tricomas en zonas altas. 
Material examinado. COLOMBIA. Chocó: Quibdó, $\mathrm{km} 7$ vía Quibdó-Yuto, finca Panelita a $64 \mathrm{~m}, 05^{\circ} 38^{\prime} 4^{\prime \prime} \mathrm{N}$, 76³8'45.9" W, 20 may 2007, (botón floral) Valoyes $Z$. \& L. Palacios 249(CHOCÓ); $\mathrm{km} 6$ vía Quibdó-Yuto, quebrada la Francisca a 64 m, 06 oct 2007, Valoyes Z., et al. 376 (CHOCÓ); Tutunendo, Estación Instituto de Investigaciones Ambientales del Pacífico, $103 \mathrm{~m}, 05^{\circ} 45^{\prime} 03.0^{\prime \prime} \mathrm{N}, 76^{\circ} 31^{\prime} 36.3^{\prime \prime}$ W, 10 oct 2007, Valoyes Z., et al. 383 (CHOCÓ); Unión Panamericana Salero, $34 \mathrm{~m}, 05^{\circ} 19^{\prime} 18.6^{\prime \prime} \mathrm{N}, 76^{\circ} 37^{\prime} 22.6^{\prime \prime} \mathrm{W}$, 13 abr 2007, Valoyes Z \& J. J. Cuestas 244 (CHOCÓ); a 34 m, 05 19'18.6" N, 76 37'22.6" W, 18 ago 2007, Valoyes Z. \& J. J. Cuestas 342 (CHOCÓ); Salero, 02 ene 2006, MoralesP, M. E., et al., 1834 (CHOCÓ, COL, FLAS); San José del Palmar: Las Partidas a 1034 m, 04 $53^{\prime} 32.2^{\prime \prime}$ N, 76 ${ }^{\circ} 14^{\prime} 55.9^{\prime \prime}$ W, 28 jul 2007, Valoyes Z., et al. 327 (CHOCÓ).

6. Blakea pilosa Gleason. Bull. Torrey Bot. Club. 72: 391.1945. Tipo: COLOMBIA. Valle del Cauca, río Calima (región del Chocó); La Trogita 5-50 m, 19 feb-10 mar 1944, J. Cuatrecas 16532 (Holotipo NY foto!).

Observaciones. De las especies que se caracterizan por presentar estípulas, registrada para el Chocó, Blakea pilosa es la única que posee nudos cubiertos por estípulas lacinadas, pardo claras; algunas características como brácteas redondeadas, multinervadas; hipanto costillado; cáliz lobulado; pétalos oblongo-lanceolados; estambres con anteras laterales oblongo-redondeadas, con poros redondos, ubican a este taxón dentro del grupo de especies afín a $B$. subconnata. De esta especie se han colectado individuos florecidos y fructificados en el mes de febrero. El material coleccionado de esta especie es escaso, situación que limita observar sus variaciones, sin embargo difiere del material tipo en la forma de las hojas y en la ausencia y presencia de indumentos, lo que se puede relacionar con el tipo de hábitat en el que se desarrolla la especie.

Hábitat y distribución. En Colombia se ha colectado en el Valle del Cauca y Chocó, en éste último se conoce por una colección realizada en el municipio de Puerto Pizarro, crece a una altura de $0-50 \mathrm{~m}$.

Material examinado. COLOMBIA. Chocó: Baudó: A lo largo del río Baudó, 16 Feb 1967, Fuchs, H. P., et al. 21883 (COL).

7. Blakea stipulacea Wurdack Phitologia VI. 4 (1957). Tipo: COLOMBIA. Valle del Cauca, monte la Guarida, filo de la cordillera Occidental, vertiente occidental, 18 oct 1946, Cuatrecasas 22241 (Holótipo NY foto!, Isotipo F) .

Hábitat, distribución y fenología. En Colombia se distribuye en Antioquia, Valle del Cauca y Chocó, en éste último se conoce por una colección realizada en San José del Palmar, crece a una altura de $2000 \mathrm{~m}$. De esta especie se han colectado individuos florecidos en los meses de febrero, mayo y octubre.

Observaciones. Blakea stipulacea crece en zonas altas, presenta hábito arbóreo, nudos con estípulas laceradas, caducas y estructuras vegetativas cubiertas por tricomas estrigosos y simples; de esta especie se tiene poca documentación ya que solo existe un registro para la región.

Material examinado. COLOMBIA. Chocó: San José del Palmar: Carretera Anserma Nuevo, límite con el Valle del Cauca, Alto del Galápago, 2000 m, 19 feb 1977, Forero E., et al. 2925 (COL).

8. Blakea vallensis Wurdack, Phytologia 69 (5): 326 (1990). Tipo: COLOMBIA: Valle del Cauca, Cerro el Inglés, Serranía de los Paraguas a 2430 m, 1 abr 1988, SilverstoneSpokin, P., et al. 3912 (Holótipo CUVC!, US foto!).

Observaciones. Blakea vallensis se distingue de sus afines como B. andreana y B. cuatrecasii, por presentar estructuras vegetativas glabras, envés foliar con nerviación secundaria prominente; pecíolos y pedicelos con lenticelas; brácteas externas glabras, poco fusionadas en la base, elípticas-obovadas, con ápice redondeado; cáliz entero; pétalos rosado pálidos y márgenes rosadas intensas, pistilo glabro.

Material examinado. COLOMBIA. Chocó: San José del Palmar: Cerro del Torrá $2500 \mathrm{~m}, 25$ ago 1988, SilverstoneSpokin, P., et al. 4795, 4648 (CHOCÓ); 4795 A, 4290 A, 4648 (CUVC); Galápago, a $1968 \mathrm{~m}, 04^{\circ} 49^{\prime} 55.1^{\prime N}$, $76^{\circ} 11^{\prime} 51.9^{\prime \prime} \mathrm{W}, 25 \mathrm{jul} 2007$, Valoyes Z., et al. 278 (CHOCÓ).

\section{CONCLUSIONES}

La variabilidad en algunos caracteres como el hábito, forma y tamaño de las hojas e indumentos en algunas estructuras de estas plantas, posiblemente se deba a respuestas ambientales físicas, climáticas o edáficas, las cuales se relacionan con la fisiogeografía del terreno, los requerimientos de luz y la temperatura. Es decir, a medida que disminuye la temperatura, las plantas modifican sus estructuras externas para protegerse del frío; de la misma forma, en tierras bajas donde existe mayor competencia de luz estas especies adquieren el hábito epífito y hemiepífito, lo que les permite ubicarse en lugares privilegiados para obtener la energía lumínica suficiente para realizar su proceso fotosintético. Por otro lado, en tierras bajas donde el terreno es plano estas son de hábito epífito, caso contrario al de tierras altas donde el tamaño y grosor de las plantas se modifican, estas mismas especies se ubican en áreas con pendientes y modifican su hábito de crecimiento a plantas arbustivas, en muchas ocasiones con tallos postrados de donde se desarrollan varias ramificaciones.

\section{AGRADECIMIENTOS}

Los autores expresan su agradecimiento al grupo de investigación en Biosistemática de la Universidad Tecnológica del Chocó «Diego Luis Córdoba»; a nuestros colegas 


\section{Bioetnia Volumen 8 No 2 (julio-diciembre), 2011}

Leonardo Palacios Duque, Jhon Jairo Cuesta Sánchez y Leider Palacios Palacios por sus valiosos aportes; al director del Herbario CHOCÓ Yan Arley Ramos Palacios; al profesor Orlando Rivera del Instituto de Ciencias de la Universidad Nacional de Colombia y al Herbario COL por facilitar la revisión de material y sus oportunos comentarios respecto a este trabajo. A la Universidad Nacional de Colombia, a la Universidad Pedagógica y Tecnológica de Colombia, al Herbario UPTC y al Instituto Colombiano para el Desarrollo de la Ciencia y la Tecnología «Francisco José de Caldas» (COLCIENCIAS), por el apoyo al segundo autor (MEM), a través de la beca de Doctorados Nacionales otorgada bajo el número 43/03.

\section{LITERATURA CITADA}

Almeda, F. 1974. A new epiphytic Blakea (Melastomatáceae) from Panama. Brittonia 26 (4): 339-97.

Almeda, F. 1990. New species and new combinations in Blakea and Topobea (Melastomataceae), with an historical perspective on generic limits in the tribe Blakeeae. Pro Calif Acad Sci. 46: 299-326.
Almeda, F. 2000. A synopsis of the genus Blakea (Melastomataceae) in Mexico and Central America. Novon 10: 299-319.

Almeda, F. 2001. Melastomataceae. In: W. D. Stevens, C. Ulloa Ulloa, A. Pool, O. M. Montiel (eds.). Flora de Nicaragua. Monographs in Systematic Botany. Missouri Bot Garden. 85: 1339-419.

Calderón-S. E., H. Mendoza-C. 2000. Melastomatáceas de los géneros Axinaea, Blakea, Castratella, Centronia, Killipia, Meriania, Monochaetum, Ossaea y Tibouchina en Colombia. Biota Colomb. 1 (3): 336-57.

Font Quer, P. 1973. Diccionario de botánica. Barcelona: Labor SA

Gleason, H. A. 1925. Estudies on the flora of Northern South America -VIII. Additional new species of Melastomataceae. Bull Torrey Bot Club. 52 (8): 447-60.

Gleason, H. A. 1945. On Blakea and Topobea. Bull Torrey Bot Club. 72 (4): 385-93.

Hickey, L. J. 1973. Classification of the architecture of dicotyledonous leaves. Am J Bot. 60: 17.33 .

Moreno, N. P. 1984. Glosario botánico ilustrado. México DF: Instituto Nacional de Investigaciones sobre Recursos Bióticos.

Uribe, U. L. 1971. Sertula Florae Colombiae, XII. Caldasia 11 (51): 81-91.

Wurdack, J. J. 1957. Certamen Melastomataceis. V. Phytologia. 6 (1): 1-11.

Wurdack, J. J. 1973. Melastomataceae. En: Lasser (ed.). Flora de Venezuela. $8(1-2): 1-819$

Wurdack, J. J. 1980. Melastomataceae. p. 406. En: Harling, G., B. Sparre. (eds.). Flora of Ecuador. $\mathrm{N}^{\circ}$ 13. Stockholm: Univ. Goteborg, Swedish Natural Science Research Council. 